\title{
Simple laparoscopic gastrostomy using a homemade hook-pin
}

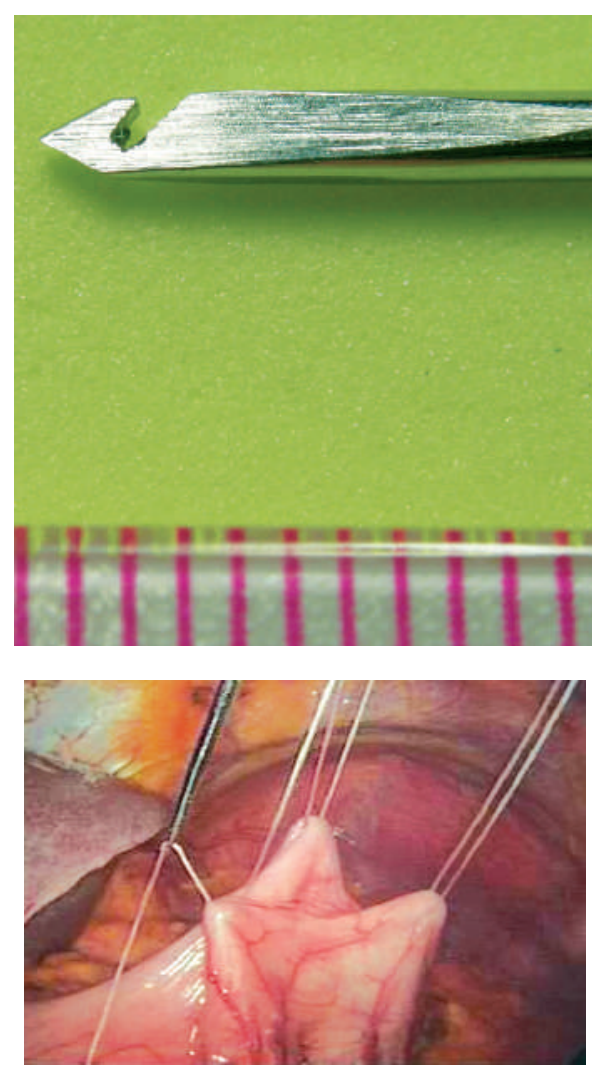

Figure 2 One end of the polypropylene is picked up by the hook-pin and is seen here being pulled through the abdominal wall.

Laparoscopic gastrostomy offers an alternative technique for the provision of long-term enteral access. Gastropexy is an important step in the procedure for placement of a gastrostomy tube [1,2]. Several gastropexy techniques have been suggested with the aim of minimizing peritoneal leakage [3-5]. These methods are sometimes expensive, complicated, and time-consuming. We have developed a modified technique for laparoscopic gastrostomy with gastropexy, using a simple homemade device.

After creating a pneumoperitoneum and placing the trocars, the site proposed for the gastrostomy is selected. A straight needle on a 2-0 polypropylene suture is inserted vertically to the abdominal skin, corresponding to the site of the stay stitch on the anterior gastric wall. The needle is then passed through the gastric wall, with the other end of the polypropylene re-
Figure 1 The hookpin device was easily made by modifying a pin used in orthopedic surgery. The device is $20 \mathrm{~cm}$ in length and has a hook near the tip for catching hold of the suture.
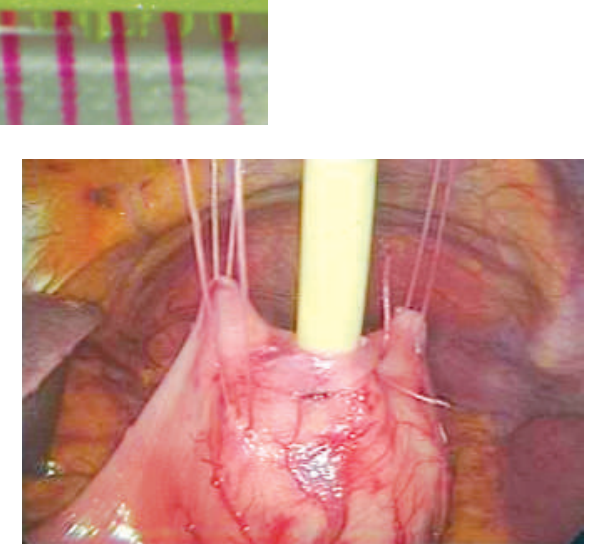

Figure 3 Three stay stitches are placed and a Foley catheter is inserted.

maining above the skin. A special homemade hook-pin (Figure $\mathbf{1}$ ) is inserted into the intraperitoneal space to pick up the other end of the polypropylene once again, and the polypropylene is then pulled through the abdominal wall (Figure 2). Three stay stitches are made in the same way, forming a triangle around the site chosen for the tube placement. By pulling the stay stitches to suspend the gastric wall, a 16-Fr Foley catheter is introduced into the stomach through the abdominal wall and then secured by a concentric purse-string suture. After the balloon is inflated, the stomach is tightly attached to the parietal peritoneum of the abdominal wall by pulling the stay stitches (Figure 3 ). The sutures are finally fixed and tied onto the abdominal skin.

The technique has been used in ten patients with excellent results and short operating times (mean operating time \pm standard deviation, $34 \pm 9$ minutes). Gastropexy is the key technique of our procedure, and this was a safe, cheap, and reproducible method which was quickly and easily accomplished using our specially made device.

Endoscopy_UCTN_Code_TTT_1AT_2AC

\section{J.-S. Hsieh, C.-F. Wu, F.-M. Chen, C.-J. Huang, T.-J. Huang}

Department of Surgery, Kaohsiung Medical University, Kaohsiung, Taiwan.

\section{References}

\begin{abstract}
${ }^{1}$ Shellito PC, Malt RA. Tube gastrostomy: techniques and complications. Ann Surg 1985; 201: 180- 185

${ }^{2}$ Dewald CL, Hiette PO, Sewall LE et al. Percutaneous gastrostomy and gastrojejunostomy with gastropexy: experience in 701 procedures. Radiology 1999; 211: 651 -656

${ }^{3}$ Peitgen K, Walz MK, Krause U et al. First results of laparoscopic gastrostomy. Surg Endosc 1997; 11: 658-662

${ }^{4}$ Murayama KM, Johnson TJ, Thompson JS. Laparoscopic gastrostomy and jejunostomy are safe and effective for obtaining enteral access. Am J Surg 1996; 172: 591 - 594

${ }^{5}$ Duh QY, Way LW. Laparoscopic gastrostomy using T-fasteners as retractors and anchors. Surg Endosc 1993; 7: 60-63
\end{abstract}

\section{Corresponding author}

\section{C.-J. Huang, MD}

Department of Surgery

Faculty of Medicine

College of Medicine

Kaohsiung Medical University Hospital

No. 100, Tzyou 1st Road

Kaohsiung City 807

Taiwan

Fax: $\quad+886-7-3114679$

Email: chjehu@kmu.edu.tw 